\title{
T-cell-mediated regulation of neuroinflammation involved in neurodegenerative diseases
}

\author{
Hugo González $z^{1}$ and Rodrigo Pacheco ${ }^{1,2^{*}}$
}

\begin{abstract}
Neuroinflammation is involved in several neurodegenerative disorders and emerging evidence indicates that it constitutes a critical process that is required for the progression of neurodegeneration. Microglial activation constitutes a central event in neuroinflammation. Furthermore, microglia can not only be activated with an inflammatory and neurotoxic phenotype (M1-like phenotype), but they also can acquire a neurosupportive functional phenotype (M2-like phenotype) characterised by the production of anti-inflammatory mediators and neurotrophic factors. Importantly, during the past decade, several studies have shown that CD4 ${ }^{+}$T-cells infiltrate the central nervous system (CNS) in many neurodegenerative disorders, in which their participation has a critical influence on the outcome of microglial activation and consequent neurodegeneration. In this review, we focus on the analysis of the interplay of the different sub-populations of $\mathrm{CD}^{+}{ }^{+}$T-cells infiltrating the CNS and how they participate in regulating the outcome of neuroinflammation and neurodegeneration in the context of Parkinson's disease, Alzheimer's disease, amyotrophic lateral sclerosis and multiple sclerosis. In this regard, encephalitogenic inflammatory CD4 ${ }^{+}$T-cells, such as Th1, Th17, GM-CSF-producer CD4 ${ }^{+}$T-cells and $\gamma \delta T$-cells, strongly contribute to chronic neuroinflammation, thus perpetuating neurodegenerative processes. In contrast, encephalitogenic or meningeal Tregs and Th2 cells decrease inflammatory functions in microglial cells and promote a neurosupportive microenvironment. Moreover, whereas some neurodegenerative disorders such as multiple sclerosis, Parkinson's disease and Alzheimer's disease involve the participation of inflammatory CD4 ${ }^{+}$T-cells 'naturally', the physiopathology of other neurodegenerative diseases, such as amyotrophic lateral sclerosis, is associated with the participation of anti-inflammatory CD4 ${ }^{+} \mathrm{T}$-cells that delay the neurodegenerative process. Thus, current evidence supports the hypothesis that the involvement of $\mathrm{CD} 4^{+} \mathrm{T}$-cells against CNS antigens constitutes a key component in regulating the progression of the neurodegenerative process.
\end{abstract}

Keywords: Neuroinflammation, Neurodegenerative disorders, Microglia, CD4+ T-cells

\section{Introduction}

The neuroinflammatory process has been associated with most neurodegenerative diseases including Alzheimer's disease (AD), Parkinson's disease (PD), multiple sclerosis (MS) and amyotrophic lateral sclerosis (ALS) [1]. Furthermore, emerging evidence indicates that neuroinflammation constitutes a critical process for the progression of neurodegeneration involved in neurodegenerative disorders [2]. Microglial activation plays a central role in neuroinflammation, with microglial cells being the main source of reactive oxygen species (ROS) and nitrogen species,

\footnotetext{
* Correspondence: rodrigo.pacheco@cienciavida.cl

${ }^{1}$ Laboratory of Neuroimmunology, Fundación Ciencia \& Vida, Avenida Zañartu \#1482, Ñuñoa 7780272 Santiago, Chile

2Departamento de Ciencias Biológicas, Facultad de Ciencias Biológicas, Universidad Andrés Bello, 8370146 Santiago, Chile
}

glutamate and TNF- $\alpha$, all of which are highly neurotoxic when released in high doses by activated microglia [2-5].

Several studies have shown that microglial activation may be evoked by the stimulation of toll-like receptors (TLRs) through the aggregated proteins in the central nervous system (CNS) of individuals with neurodegenerative diseases, as well as in animal models [6-9]. For instance, a pathological hallmark in the brain of $\mathrm{AD}$ patients includes extracellular deposition of the fibrillar form of $\beta$-amyloid peptide $(A \beta)$ surrounded by dystrophic neurites, forming senile plaques and intracellular neurofibrillary tangles constituted of hyperphosphorylated forms of the microtubule-binding protein Tau [10]. Similarly to $\mathrm{AD}, \mathrm{PD}$ is a proteinopathy that is characterised by the accumulation and aggregation of misfolded $\alpha$-synuclein and ubiquitin in cytoplasmic inclusions called Lewy bodies 
and Lewy neurites. These cytoplasmic inclusions are found in both sporadic and inherited forms of PD [11]. Similarly, ALS involves the aggregation of superoxide dismutase 1 (SOD1) in the CNS [12]. Other examples include associations of aggregated huntingtin in Huntington's disease, Prp-amyloid in prion disease and Reelin in aging brain [1].

Similar to the functional behaviour of peripheral macrophages [2], microglia can not only be activated with an inflammatory and neurotoxic phenotype (M1-like phenotype), but they can also acquire a neurosupportive functional phenotype (M2-like phenotype), characterised by the production of anti-inflammatory mediators and neurotrophic factors, including insulin-like growth factor 1 (IGF-1), brain-derived neurotrophic factor (BDNF), glial cell-derived neurotrophic factor (GDNF), among others [13-15]. Intercellular interactions between microglia and other cellular factors play a fundamental role in the outcome of the functional phenotype acquired by activated microglia and, therefore, in neurodegeneration. Cellular factors influencing microglial fate include astrocytes, neurons, epithelial cells of the blood-brain barrier (BBB) and T-cells infiltrating the CNS [2]. Indeed, during the last decade, several studies have shown that $\mathrm{CD} 4^{+} \mathrm{T}$-cells infiltrate the CNS in many neurodegenerative disorders, and that their participation has a critical influence on the outcome of microglial activation and consequent neuronal damage [1,2].

The precise role of $\mathrm{CD}^{+}{ }^{+} \mathrm{T}$-cells infiltrating the CNS in the outcome of neuroinflammation strongly depends on the functional phenotype of these cells [2]. Naïve $\mathrm{CD} 4^{+}$T-cells may be activated by antigen-presenting cells (APCs) in the presence of diverse mediators and, depending on the precise composition of the mediators milieu, they can differentiate different functional phenotypes, each of them specialised in orchestrating an immune responses against a different kind of threat. For instance, in the presence of IL-12, the differentiation of $\mathrm{CD} 4^{+} \mathrm{T}$-cells toward the T-helper 1 (Th1) phenotype is favoured, representing a functional phenotype specialised in the elimination of intracellular pathogens. Furthermore, this inflammatory phenotype has been associated with neuroinflammation and neuronal damage $[16,17]$. The acquisition of the inflammatory Th1 phenotype is controlled by the master transcription factor Tbet, and the main effector cytokine produced by these cells is IFN- $\gamma[18]$. Another important inflammatory functional phenotype associated with neuroinflammation and neurodegeneration is the Th17 phenotype, which is favoured by the presence of IL-23 during the activation of naïve $\mathrm{CD} 4^{+}$ T-cells. These cells normally play an important role in gut immunity, as their phenotype is controlled by the master transcription factor ROR $\gamma$ t and their main effector cytokines are IL-17 and IL-22 [18]. On the other hand, differentiation of the functional phenotype Th2 is controlled by the master transcription factor GATA3, which is favoured by the action of IL-4, and their main effector cytokines are IL-13, IL-5 and IL-4. This effector phenotype not only plays a fundamental role in the orchestration of immunity against helminths and in allergy [19], but is also involved in the attenuation of neuroinflammatory processes and contributes to the consolidation of spatial memory under physiological conditions [20-24]. CD4 ${ }^{+}$ T-cells can also acquire an anti-inflammatory functional phenotype, the T-regulatory phenotype (Treg), which can suppress the inflammatory function of effector T-cells [13]. Tregs cells are normally involved in the maintenance of tolerance toward self-constituents, limiting inflammatory responses against foreign antigens and, importantly, they are also known to be involved in the attenuation of neuroinflammation and consequent neurodegeneration [25-28]. During recent years, these functional phenotypes of $\mathrm{CD}_{4}^{+} \mathrm{T}$-cells have been shown to participate in the physiopathology of neurodegenerative disorders. In this study, we focus on the analysis of the interplay between the different sub-populations of $\mathrm{CD}^{+}{ }^{+} \mathrm{T}$-cells and how they participate in regulating the outcome of neuroinflammation and neurodegeneration in the context of PD, AD, ALS and MS. Furthermore, in the last part of this review, we analyse the participation of peripheral monocytes/ macrophages infiltrating the CNS, their interaction with T-cells and their contribution to the regulation of neuroinflammation.

\section{Role of T-cells infiltrating the CNS parenchyma in multiple sclerosis}

MS represent a neurodegenerative disease in which a T-cell-mediated response has been known to be involved for more than a decade. MS is a chronic demyelinating disease generated by an autoimmune response against constituents of the CNS. This autoimmune disease affects approximately 2.4 million individuals worldwide [29]. MS is characterised by the progressive loss of neurological function caused by the destruction of the axonal myelin sheath in several areas of the brain and the spinal cord, which is mediated, mainly, by self-reactive $\mathrm{CD} 4^{+} \mathrm{T}$-cells [30]. The loss of myelin is manifested in clinical symptoms such as paralysis, muscle spasms, optic neuritis and neuropathic pain [31]. The pathological features of MS lesions involve BBB permeability, myelin sheath destruction, axonal damage, glial scar formation and the presence of inflammatory cells, mostly lymphocytes, infiltrated into the CNS [32]. The most used and accepted animal model equivalent of MS is experimental autoimmune encephalomyelitis (EAE), which corresponds to an induced autoimmunity in mice. EAE may be triggered in mice upon injection of peptides derived from myelin emulsified with adjuvant 
[33]. The administration of myelin-derived antigens in an immunogenic context induces the activation of selfreactive $\mathrm{T}$-cells that are specific for myelin antigens, mediating myelin destruction. This induced autoimmunity is characterised by focal areas of demyelination along the brain and spinal cord, with axonal loss that results in ascending paralysis, affecting first the tail and then the hind limbs. Self-reactive $\mathrm{CD}_{4}^{+} \mathrm{T}$-cells are activated by auto-antigen-presenting dendritic cells in peripheral lymph nodes and, then, the activated self-reactive CD $4^{+}$ T-cells migrate into the CNS parenchyma. Self-reactive Th17 cells are the first T-cell population to infiltrate the $\mathrm{CNS}$, as they express $\mathrm{C}-\mathrm{C}$ chemokine receptor 6 (CCR6), which recognises $\mathrm{C}-\mathrm{C}$ chemokine ligand 20 (CCL20) that is constitutively expressed on epithelial cells from the choroid plexus [34]. Th17 cells infiltrating the CNS are restimulated once inside the CNS by resident APCs, which is followed by microglia activation and production of IL- $1 \beta$, TNF- $\alpha$ and IL-6, which contribute to myelin sheath damage [35]. This initial neuroinflammatory process results in $\mathrm{BBB}$ disruption and the entrance of leukocytes into the CNS parenchyma. Once T-cells enter the CNS, they are re-stimulated by resident APCs, such as astrocytes, microglia or infiltrated APCs such as dendritic cells and macrophages [36]. Thereby, APCs play an important role during the course of EAE, as they are involved in the peripheral activation of T-cells as well as in the re-stimulation of T-cells inside the CNS. Infiltration of T-cell into the CNS and their local re-stimulation lead to the manifestation of clinical symptoms [37]. Although there are several studies indicating that Th17 and Th1 cells infiltrate the CNS during the course of EAE, recent studies have shown that none of their signature cytokines are essential for the development of this disease. In contrast to the expression of IL-17 and IFN- $\gamma$, the production of granulocyte macrophage-colony-stimulating factor (GM-CSF) by autoreactive CD4 ${ }^{+}$T-cells has proven to be essential for the development of EAE [38,39]. The production of this cytokine is stimulated by IL-23 and by the expression of both transcription factors ROR $\gamma \mathrm{t}$ and Tbet, whereas it is inhibited by IL-12, IFN- $\gamma$ and IL-27 $[38,40]$. On the other hand, Tregs progressively infiltrate the CNS, starting at disease onset. However, the generation of Tregs and the suppressive activity of CNS-infiltrated Tregs is impaired by $\gamma \delta$ T-cells [27]. $\gamma \delta \mathrm{T}$-cells infiltrate the CNS during EAE, starting at the onset of disease, reaching the highest cell number at the peak of disease manifestation before progressively disappearing from the CNS, thus correlating with the time course of EAE manifestation [27]. $\gamma \delta \mathrm{T}$-cells inhibit the function of Tregs cells and produce large amounts of IL-17 in response to IL-23. Once $\gamma \delta$ T-cells begin disappearing from the CNS, Tregs continue to progressively infiltrate the CNS and they can recover their suppressive activity, which correlates to the progressive attenuation of EAE manifestation [27]. Another kind of T-cell that is relevant for EAE is the $\mathrm{CD} 8^{+}$population. In this regard, some studies involving cell transfer have suggested the participation of $\mathrm{CD}^{+} \mathrm{T}$-cell subpopulations in a pathogenic role of EAE [41]. On the other hand, there is strong evidence to indicate the participation of a regulatory sub-population of $\mathrm{CD}^{+}$ T-cells, which play a beneficial role in EAE $[42,43]$. Studies show that EAE is more severe in mice that are deficient in or depleted of $\mathrm{CD}^{+}{ }^{+} \mathrm{T}$-cells, and the disease severity has been inversely correlated with the frequency of $\mathrm{CD}^{+}$T-cells infiltrating the CNS [41]. In this regard, distinct sub-populations of $\mathrm{CD}^{+}$Tregs have been described, including $\mathrm{CD}^{+} \mathrm{CD} 28^{-}, \mathrm{CD}^{+} \mathrm{CD} 122^{+}$and $\mathrm{CD}^{+} \mathrm{LAP}^{+}$[44-46]. Importantly, the frequency of $\mathrm{CD}^{+}$ T-cells is greater than that of $\mathrm{CD}^{+}{ }^{+} \mathrm{T}$-cells in inflamed plaques from MS patients, and $\mathrm{CD}^{+} \mathrm{T}$-cells show oligoclonal expansion in plaque, cerebrospinal fluid and blood, suggesting an important role of this cell population in MS. Taken together, these data indicate the complex role of several T-cell populations in MS, which finally regulate microglial activation and, therefore, the outcome of neuroinflammation. An overview of the role of the different T-cell populations participating in neuroinflammation associated with MS is schematised in Figure 1.

\section{Involvement of T-cell-mediated immune response in Parkinson's disease}

$\mathrm{PD}$ is the second most common neurodegenerative disease after AD. PD is characterised by the loss of 50 to $70 \%$ of dopaminergic neurons located in the substantia nigra pars compacta $(\mathrm{SN} p c)$. The progressive degeneration of dopaminergic fibres in the brain results in prominent motor symptoms, such as bradykinesia, tremors, rigidity and postural instability. Although studied less in PD than in MS, the fundamental participation of T-cells has also been described in PD. An altered frequency of peripheral $\mathrm{CD}^{+}{ }^{+} \mathrm{T}$-cells has been described in blood samples obtained from PD patients $[47,48]$. Moreover, $\mathrm{CD}^{+}$and $\mathrm{CD}^{+} \mathrm{T}$-cells that infiltrated into the brain parenchyma have been found in post-mortem samples obtained from PD patients $[49,50]$, as well as in animal models using mice [50,51] and rats [52]. Recent studies carried out with T-cell receptor (TCR)- $\beta$-chain-deficient mice, SCID mice and recombination-activating-gen-1 (RAG1) knockout (RAG1KO) mice demonstrated that T-cell deficiency results in a strong attenuation of dopaminergic neurodegeneration in 1-methyl-4-phenyl-1,2,3,6-tetrahydropyridine (MPTP)-induced PD [50,53]. This reveals that T-cells are not only relevant, but are also required for neurodegeneration in PD. Additional experiments have shown that although $\mathrm{CD}^{+}$T-cell deficiency is negligible, the participation of $\mathrm{CD}^{+}{ }^{+} \mathrm{T}$-cells is fundamental for promoting the 


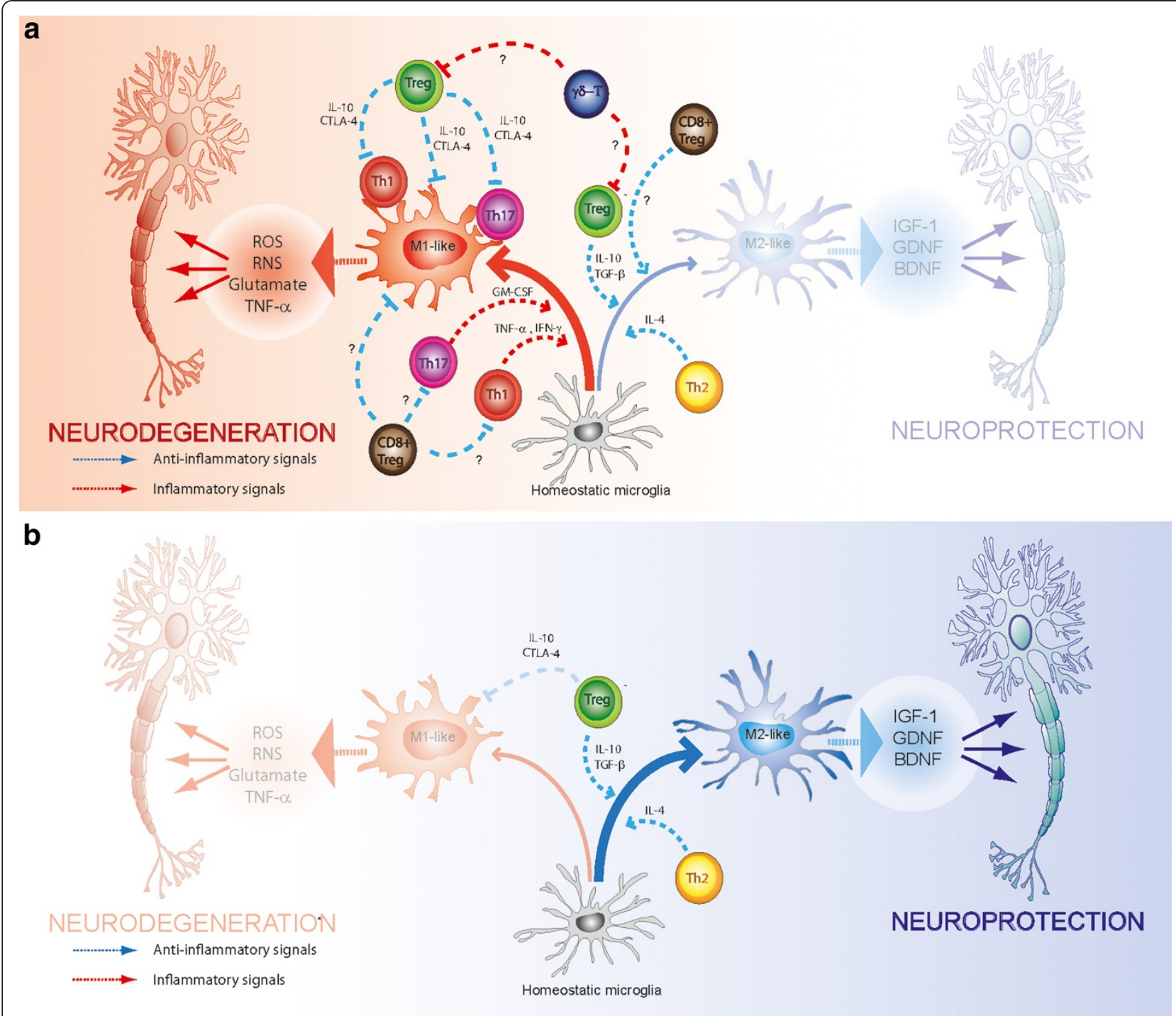

Figure 1 T-cell-mediated regulation of neuroinflammation in neurodegenerative disorders. The scheme shows how the participation of inflammatory and anti-inflammatory subsets of encephalitogenic T-cells might regulate microglial fate and, consequently, the degeneration or survival of neurons. Whereas Th1, Th17, GM-CSF-producer CD4 ${ }^{+}$T-cells and $\gamma \delta T$-cells favour the acquisition of the neurotoxic M1-like phenotype by microglia (left side of the illustration), Th2, Tregs and some kinds of $\mathrm{CD} 8^{+} \mathrm{T}$-cells can contribute to the promotion of neurosupportive M2-like phenotype in microglial cells (right side of the illustration). The scheme in (a) shows the 'natural' scenario during the progression of multiple sclerosis (MS), Parkinson's disease (PD) and Alzheimer's disease (AD), which involve the M1-like microglia and consequent neurodegeneration; however, upon disease remission or immunosuppressive interventions, it is possible to induce the M2-like phenotype of microglia and neuroprotection. In the case of PD and AD, only Th1, Th17 and Tregs cells have been associated with the regulation of neuroinflammation. The role of other T-cell subsets in the regulation of neuroinflammation associated to AD and PD remains unexplored. The scheme in (b) illustrates the participation of T-cells in the regulation of neuroinflammation associated to amyotrophic lateral sclerosis (ALS). The physiopathological scenario of this disorder 'naturally' involves the participation of encephalitogenic or meningeal Tregs and Th2 cells, which strongly contribute to the induction of the anti-inflammatory M2-like phenotype on microglial cells, thus slowing the progression of the neurodegenerative process. BDNF, brain-derived neurotrophic factor; GDNF, glial cell-derived neurotrophic factor; IGF-1, insulin-like growth factor 1; RNS, reactive nitrogen species; ROS, reactive oxygen species.

neurodegeneration of dopaminergic neurons in the SNpc of mice with PD [50]. These studies support the involvement of pathogenic $\mathrm{CD} 4^{+} \mathrm{T}$-cell populations, which would induce the acquisition of an M1-like pro-inflammatory phenotype by the microglia, which is characterised by the secretion of inflammatory factors such as TNF- $\alpha$, IL-1 $\beta$, glutamate and superoxide [14,54]. Supporting the pivotal role of $\mathrm{CD} 4^{+} \mathrm{T}$-cells potentiating microglial activation and favouring neurodegeneration in $\mathrm{PD}$, it has recently been reported that a deficiency of class II major histocompatibility complex (MHC) results in attenuation of both microgliosis and loss of dopaminergic neurons in a 
mouse model of PD [55]. Experiments addressing the phenotype of pathogenic $\mathrm{CD}_{4}^{+}$T-cells involved in PD have shown that both Th1 and Th17 autoreactive cells are important for the promotion of neuronal loss [26]. Addressing the molecular mechanisms involved in $\mathrm{CD}_{4}^{+}$ T-cell-mediated loss of dopaminergic neurons in PD, a study has shown that the participation of Fas-FasL interactions seems to contribute to the neurodegenerative process [50]. Importantly, we have recently demonstrated that dopamine receptor D3 (D3R), expressed in CD4 ${ }^{+}$ T-cells, is fundamental in inducing the loss of dopaminergic neurons in the SNpc of a PD mouse model [17]. In this regard, we and others have reported that D3Rdeficient (D3RKO) mice are resistant to MPTP-induced PD $[17,56]$. Interestingly, when wild type (WT) $\mathrm{CD}^{+}$ T-cells were transferred to D3RKO mice, the animals acquired the capability to respond to MPTP-induced neurodegeneration. On the other hand, RAG1KO mice, which are devoid of T-cells and are resistant to MPTPinduced PD, acquire the capability to respond to MPTPinduced neurodegeneration when $\mathrm{WT} \mathrm{CD} 4^{+}$T-cells were transferred, but not when D3RKO CD4 ${ }^{+}$T-cells were transferred [17]. Notably, our data indicate that the stimulation of D3R expressed on $\mathrm{CD}^{+}$T-cells favours the acquisition of Th1 inflammatory cells, thus indicating the crucial importance of this pathogenic phenotype in the $\mathrm{CD}^{+}{ }^{+} \mathrm{T}$-cells immune response that is involved in $\mathrm{PD}$ [17]. In this regard, we observed that WT, but not D3RKO, CD4 ${ }^{+}$T-cells infiltrating the $\mathrm{SN} p c$ during MPTP-induced PD produced high levels of IFN- $\gamma$ and TNF- $\alpha$, which are two cytokines that act synergistically in microglia, promoting the inflammatory M1-like phenotype [57]. Thus, these findings point towards the important role of CNS-derived dopamine in the regulation of T-cell-mediated immunity during neuroinflammation. Conversely, other T-cell subsets, such as Tregs and Th2, could contribute to microglial acquisition of an M2-like anti-inflammatory phenotype, which release neurotrophic factors, including IGF-1, promoting neuronal protection $[14,26]$. Indeed, it has been demonstrated that Tregs elicit neuroprotection for dopaminergic neurons of $\mathrm{SNpc}$ in MPTP-induced PD in mice [26,58]. Further analyses have shown that these Tregs cells act directly on activated M1-like microglial cells, attenuating migration, phagocytosis and the production of neurotoxic factors $[58,59]$. In vitro experiments have shown that Tregs-mediated inhibition of M1-like microglia functions occurred through the suppression of NF- $\mathrm{B}$ activation and required not only soluble mediators from Tregs, but also cell-cell contacts with microglial cells [59]. Another group of studies have also shown evidence of the neuroprotective role of Tregs in PD. In these studies, copolymer-1 was used as an immunogen, which is a potent inducer of encephalitogenic Tregs [60]. It has been shown that adoptive transference of CD4 ${ }^{+}$
T-cells isolated from mice, immunised with copolymer-1, attenuates the neurodegeneration of dopaminergic neurons in SNpc of mice with MPTP-induced PD [61]. On the other hand, Reynolds et al. found that Th2 cells, which are specific against CNS antigens involved in PD, do not play a relevant role, exacerbating or attenuating neurodegeneration in MPTP-induced PD [26]. Other encephalitogenic T-cell subsets described as playing important inflammatory or anti-inflammatory roles in MS have not yet been studied in PD. Thus, future efforts are necessary to elucidate the participation of anti-inflammatory $\mathrm{CD}^{+}$T-cell subsets, inflammatory $\gamma \delta \mathrm{T}$-cells and GM-CSF-producer T-helper cells in the physiopathology of PD. An integrative summary of the role of T-cells in the neurodegenerative process associated with PD is shown in Figure 1.

\section{T-cell-mediated immune response associated with Alzheimer's disease}

$\mathrm{AD}$ is the most common neurodegenerative disorder worldwide, and it leads to irreversible cognitive impairment and important behavioural alterations. Similar to $\mathrm{PD}, \mathrm{T}$-cells have been detected as infiltrating the brain parenchyma in close proximity with $\mathrm{A} \beta$ deposits in postmortem samples of AD patients and in mouse models of $\mathrm{AD}[62,63]$. Consistent with this observation, $\mathrm{A} \beta$-reactive T-cells have been found in peripheral blood obtained from AD patients [64]. Interestingly, A $\beta$-specific T-cell response was highly dependent on a particular epitope. IFN- $\gamma$ has been shown to play an important role in T-cell-mediated responses involved in AD. Limited expression of IFN- $\gamma$ in the brain favoured T-cell infiltration into the CNS parenchyma and the formation of immunosynapses with microglia in a mouse model of AD [62]. Moreover, recent data indicate that IFN- $\gamma$ produced by T-cells infiltrating the brain in AD favour increased microglial activation, $\mathrm{A} \beta$ deposition and impaired cognitive functions [16]. Indeed, systemic administration of anti-IFN- $\gamma$ antibody in mice with $\mathrm{AD}$ decreased microglial activation and $\mathrm{A} \beta$ deposition, and improve cognitive functions [16]. Interestingly, vaccination with $A \beta$ peptide has proved efficacious in $A D$ mouse models [65]. In this regard, transcutaneous immunisation with aggregated $A \beta$ plus the adjuvant cholera toxin results in a high titre of anti-A $\beta$ antibodies and a significant decrease in cerebral $A \beta$ aggregated in mice with AD [24]. The fact that most anti-A $\beta$ antibodies were of IgG1 isotype in this vaccine can be explained by the induction of a Th2-mediated immune response using this therapeutic approach; this represents a kind of immune response that promotes a switch-on microglial M2-like phenotype with consequent neuroprotection $[14,21,25,66,67]$. Notably, in the study carried out by Nikolic et al., they did not detect T-cell infiltration in the brain parenchyma [24]. Thereby, it is possible that, when Th2 responses are induced against CNS antigens, 
CD $4^{+}$T-cells mainly act from meningeal space, affecting glial function without infiltrating the brain parenchyma, as seen in healthy animals $[21,66]$. The role of Tregs has also been addressed in AD. The adoptive transference of Tregs significantly ameliorates impaired cognition and reduces the $A \beta$-deposits and microglial activation in a mouse model of AD [25]. Moreover, higher Tregs function has been associated with lower cognitive manifestation in AD patients [68]. Addressing the participation of different inflammatory phenotypes of $\mathrm{CD}^{+}{ }^{+} \mathrm{T}$-cells infiltrating the brain during $\mathrm{AD}$, studies indicate an important role for both Th1 and Th17 cells. In this regard, Browne et al. examined the role of $\mathrm{A} \beta$-specific $\mathrm{CD}^{+}{ }^{+} \mathrm{T}$-cells on $\mathrm{A} \beta$ accumulation in transgenic mice that overexpress amyloid precursor protein and presenilin-1. The results revealed that $A \beta$-specific Th1 and Th17 cells infiltrate the brain in this AD model. To address the relevance of the different $\mathrm{CD}^{+}{ }^{+} \mathrm{T}$-cell phenotypes in $\mathrm{AD}$, the same authors generated $\mathrm{A} \beta$-specific $\mathrm{CD} 4^{+} \mathrm{T}$-cells by immunisation of WT mice with $\mathrm{A} \beta$ and a TLR agonist, and then polarised them in vitro towards Th1, Th2 or Th17, which were then adoptively transferred into mice with AD. Their results showed that Th1 cells, but not Th2 or Th17 cells, increased microglial activation and $\mathrm{A} \beta$ deposition, and these changes were associated with impaired cognitive function [16]. Thus, this data indicates a leading role of inflammatory Th1 cells in the immune response associated with AD. However, there is a group of studies supporting the relevance of the participation of Th17 cells in the immune response associated with $\mathrm{AD}$. In this regard, the phenotypic analysis of circulating T-cells obtained from AD patients has shown higher frequencies of the activation marker CD25 and of CCR6, which is characteristic of Th17 cells [69], an inflammatory phenotype associated with neuronal damage in MS and PD [26,30]. Moreover, significant infiltration of Th17 cells has been detected in the hippocampus by the immunodetection of the master transcription factor ROR $\gamma \mathrm{t}$ and the expression of Th17 cytokines IL-17 and IL-22, which have been associated with neuron loss and gliosis in cornu ammonis area 1 (CA1) in a rat model of AD [70]. Furthermore, immunohistochemical analyses in brain sections of $\mathrm{AD}$ animals showed a high expression of Fas in the hippocampal neurons and a high expression of FasL in Th17 cells that were in close proximity with neurons. Thus, these findings suggest that Th17 cells, which were infiltrated into the hippocampus parenchyma, participate in neuroinflammation and neurodegeneration of $\mathrm{AD}$ by releasing proinflammatory cytokines and by inducing neuron apoptosis mediated by Fas-FasL contacts [70]. Taken together, the current evidence indicates that inflammatory Th1 and Th17 CD4 ${ }^{+}$T-cells play an important role in the physiopathology of $\mathrm{AD}$, favouring the disease progression (Figure 1). Nevertheless, other important encephalitogenic
T-cell subsets that play important inflammatory or antiinflammatory roles in MS have not yet been studied in AD. Furthermore, studies implementing the genetic deletion of specific subsets of inflammatory or antiinflammatory T-cells would be very helpful in order to clarify the specific roles and relevance of these different T-cell subsets in the development and progression of AD. Therefore, similar to the case for PD, future efforts are required to evaluate the participation of important T-cell subsets, such as $\gamma \delta \mathrm{T}$-cells and GM-CSF-producer T-helper cells, in the physiopathology of AD.

\section{Involvement of T-cell function in the pathogenesis of amyotrophic lateral sclerosis}

ALS is a neurodegenerative disorder characterised by selective and progressive degeneration of upper and lower motor neurons, leading to dramatic muscle paralysis and death. The initial cause of ALS remains unclear, but nearly $2 \%$ of patients have mutations in the $\mathrm{Cu} / \mathrm{Zn}$ SOD1 gene, which codes for a ubiquitous protein that acts in removing dangerous superoxide radicals from inside the cell. It has recently been proposed that both loss of dismutase activity and protein aggregation of SOD1 are involved in triggering neuronal loss in ALS [12]. Transgenic mice that overexpress human mutant SOD1 (mSOD1) develop motor pathology resembling ALS [71]. Similar to that occurring in other neurodegenerative diseases such as PD, AD and MS, neuroinflammation is a prominent feature in the process of neuronal loss in ALS patients, as well as in animal models of ALS [1]. Accumulating evidence has emerged during recent years, indicating that the adaptive immune system plays an important role in regulating the progression of ALS [20,23,72]. Interestingly, T-cell infiltration in spinal cords of ALS mice has been described in close proximity with dying motor neurons and has been associated with glial activation [20,23,72]. Nevertheless, the exact role of the direct interaction of T-cells with motor neurons in ALS remains unclear. Studies addressing the role of T-cells in ALS have shown that T-celldeficient mice with ALS, generated by crossing mSOD1 transgenic mice with RAG2KO or with TCR $\beta$-chain knockout (TCR $\beta K O)$ mice, develop an accelerated progression to the symptomatic stage of ALS [20,23]. Furthermore, T-cell deficiency in mice models of ALS is associated with accelerated neuronal loss and decreased glial activation. Moreover, the reconstitution of mSOD1/ RAG2KO mice with functional T-cells has shown to recover a prolonged survival of ALS mice, increased glial activation and delayed neuronal loss [20]. Further experiments have shown that mSOD1/CD4KO mice display a phenotype resembling that observed in $\mathrm{mSOD} 1 /$ RAG2KO mice, thus attributing the neuroprotective role to $\mathrm{CD}^{+}{ }^{+}$T-cells, but not to $\mathrm{CD}^{+}$T-cells or B-cells [20]. Importantly, ALS mice show microgliosis and astrogliosis 
in the spinal cord, and T-cell deficiency does not significantly affect astrogliosis. However, when lacking T-cells or, specifically, $\mathrm{CD}^{+}{ }^{+}$T-cells, ALS mice display microglial cells with attenuated morphological microgliosis, decreased activation markers such as CD11b and CD68, increased levels of pro-inflammatory cytokines such as IL- 6 and TNF- $\alpha$, decreased levels of trophic factors such as IGF-1, GDNF and BDNF as well as elevated levels of nicotinamide adenine dinucleotide phosphate (NADPH) oxidase 2, which is known to enhance microglial release of ROS [20,23]. All these data indicate that CD4 ${ }^{+}$T-cells play a regulatory role on microglial cells during ALS progression, providing supportive neuroprotection by favouring the acquisition of the M2-like phenotype by microglial cells. Recent evidence suggests that both Tregs as well as Th2 cells actively contribute to the neuroprotective effect exerted by $\mathrm{CD}^{+} \mathrm{T}$-cells over microglia. In this regard, analysis of peripheral blood $\mathrm{CD} 4^{+} \mathrm{T}$-cells obtained from ALS patients has shown decreased levels of Tregs and a decreased level of protein FoxP3 expression, both of which result in a lower suppressive activity [73]. Both parameters were reduced in rapidly progressing ALS patients, and inversely correlated with the progression rates $[72,74,75]$. In addition, both the Th2 cytokine IL-4 and the master transcription factor controlling Th2 phenotype, GATA3, also became reduced in rapidly progressing patients, inversely correlating with the progression of motor symptoms [74]. Furthermore, supporting the participation of Th2 cells during ALS progression, elevated IL-4 levels were found in spinal cords that were obtained from mSOD1 mice [23]. Moreover, stimulation of microglial cells from healthy or ALS mice with IL-4 induces a strong expression of IGF-1 and attenuates the production of inflammatory cytokine IL-6 [23]. Thus, current evidence collectively suggests that, by regulating the acquisition of the functional phenotype of microglia, Tregs as well as Th2 lymphocytes would play an important neuroprotective role during ALS progression. See Figure 1 for an integrative overview of the role of T-cells in neuroinflammation in ALS.

\section{Contribution of macrophages to the neuroinflammatory process associated with neurodegenerative diseases}

Current evidence indicates that microglial cells play a key role in sensing protein aggregates in a TLR-dependent manner in the CNS of patients suffering neurodegenerative diseases [6,7]. This initial activation of microglia produces pro-inflammatory mediators, favouring BBB permeabilisation and, therefore, the infiltration of peripheral leukocytes into the CNS, including T-cells, macrophages and others [76]. Macrophages share several functional features with microglia, including: i) the expression of TLRs and, therefore, the capability of being activated by aggregated proteins or pathogen-associated molecular patterns [6,7], ii) the expression of class II $\mathrm{MHC}$ and, therefore, the capability to present antigens to $\mathrm{CD}^{+}{ }^{+} \mathrm{T}$-cells and exert an influence on the functional phenotype of T-cells [77], and iii) the ability to polarise their functional phenotype towards an inflammatory M1 phenotype versus an anti-inflammatory M2 phenotype, which can be influenced by inflammatory T-cells and Tregs [78]. Thus, when the BBB is already permeabilised, the possibility arises in which peripheral macrophages may acquire a relevant role in the outcome of neuroinflammation. In fact, there is also evidence suggesting that a strong inflammatory response in the periphery, such as systemic lipopolysaccharide (LPS) [79] or viral infections [80], may result in subsequent infiltration of peripheral leukocytes into the CNS with consequent neuroinflammation and neurodegeneration. Therefore, irrespective of where the inflammatory response is initiated (periphery versus $\mathrm{CNS}$ ), macrophages infiltrating the CNS can acquire a relevant role in the outcome of neuroinflammation associated with neurodegenerative disorders. According to this notion, there are a number of studies associating neurodegenerative disorders with alterations in molecular components, determining the M1/M2 behaviour of peripheral macrophages. In this regard, the anti-inflammatory surface molecule CD200R is decreased in monocytederived macrophages obtained from the peripheral blood of PD patients in comparison with those from healthy donors [81]. Interestingly, the same authors found that inducible expression of CD200R in monocytederived macrophages correlated inversely with the onset age of PD and with the capability of these cells to produce TNF- $\alpha$ [81]. According to the important role of chemoattraction of monocytes in inflamed tissues, as well as their relevance in neurodegenerative disorders, the polymorphism of monocyte chemoattractant protein 1 (or CCL2) has been associated with the age of PD patients at onset [82]. Similarly, a study found that peripheral blood monocytes obtained from PD patients displayed a strong up-regulation of the surface CCR2, which is the receptor for the chemokine CCL2 [83]. Furthermore, according to the relevance of monocytes/macrophages in PD, a recent study has shown that the transference of GDNF-transfected macrophages into mice undergoing 6-hydroxydopamine-induced PD results in a potent neuroprotective effect [84]. Another study addressing the analysis of these alterations in gene-expression profiling of peripheral blood mononuclear cells obtained from patients undergoing sporadic ALS found an up-regulation of TLR4-signaling-associated genes [85], thus suggesting a chronic activation of peripheral blood monocytes/macrophages in ALS. According to this idea, Butovsky et al. have found that monocytes obtained from an ALS mouse model present a polarised M1 phenotype and increased CCR2 expression [86]. The same authors have shown that the treatment of ALS mice with 
anti-Ly6C antibodies results in a partial depletion of monocytes, decreased infiltration of M1 macrophages in the spinal cord and attenuated neurodegeneration [86], thus indicating a pivotal role of monocytes/macrophages in the physiopathology of ALS. Similar to the inflammatory phenotype observed in monocytes/macrophages from PD and ALS patients, studies addressing the characterisation of peripheral blood monocytes/macrophages of $\mathrm{AD}$ patients have shown that these cells display an increased M1 phenotype, with increased expression of chemokine receptors CCR2 and CXCR1 $[87,88]$, and stronger production of inflammatory cytokines, including IL-1 $\beta$, IL-6 and IL-23 [88,89]. Regarding MS, studies analysing the M1/ M2 profile of monocytes/macrophages obtained from human blood samples are more difficult to interpret, as many studies are performed with relapsing-remitting patients and/or individuals treated with the immunomodulatory cytokine IFN- $\beta$. However, the relevance of the M1/M2 profile of monocytes/macrophages has been addressed in EAE. In this regard, M1 macrophages have been found in the early stage of acute EAE, whereas the frequency of M2 macrophages is increased during the peak of disease manifestation and throughout the recovery stage [90]. Indeed, a reduced M1/M2 ratio in the profile of monocytes/macrophages in the blood, as well as in the CNS, promotes an attenuated manifestation of the disease, whereas an increased M1/M2 ratio favours relapsing EAE [91]. Furthermore, the administration of ex vivo-activated M2 monocytes both reduces the severity of ongoing EAE and favours the expression of immunosuppressive molecular profile in CNS lesions [91]. In addition, experiments carried out in an animal model of focal demyelinisation have shown that M2 macrophages promote remyelinisation by inducing oligodendrocyte differentiation through a mechanism involving the secretion of activin-A [92]. Importantly, a study has shown that GM-CSF production by encephalitogenic CD $4^{+} \mathrm{T}$-cells is absolutely necessary for EAE manifestation, and its cellular targets were myeloid cells expressing the GM-CSF receptor [38]. Furthermore, experiments performed with bone-marrow chimeras, generating animals with selective deletion of the GM-CSF receptor in microglia or in CNS-infiltrating myeloid cells, have demonstrated that the GM-CSF receptor was required to be expressed in myeloid cells from a peripheral origin, but not in microglia, in order to allow EAE manifestation [38]. Taken together, all of these data indicate that peripheral monocytes/macrophages display an inflammatory M1 phenotype in human individuals suffering neurodegenerative disorders. Moreover, evidence obtained from animal models suggests that these cells may be relevant in neuroinflammation and in the progression of neurodegeneration, and their manipulation favouring the M2 phenotype has shown promising therapeutic potential.

\section{Conclusions}

Neuroinflammation constitutes a critical process in the physiopathology of several neurodegenerative disorders, which is required for the progression of neurodegeneration. Differential activation of microglial cells constitutes a central point of regulation in neuroinflammation, which can result in neurotoxic or neuroprotective environments that are critical for the fate of neurons. Growing evidence has indicated a fundamental role of $\mathrm{CD}^{+}$T-cells in the regulation of neuroinflammation and consequent neurodegeneration in a number of neurodegenerative diseases. In this regard, encephalitogenic inflammatory CD4 ${ }^{+} \mathrm{T}$-cells such as Th1, Th17, GM-CSF-producer CD4 ${ }^{+}$T-cells and $\gamma \delta \mathrm{T}$-cells strongly contribute to feed chronic neuroinflammation, thus perpetuating neurodegenerative processes. In contrast, encephalitogenic or meningeal Tregs and Th2 cells decrease inflammatory functions in microglial cells and promote a neurosupportive microenvironment. Interestingly, whereas some neurodegenerative disorders such as MS, PD and AD involve the participation of inflammatory $\mathrm{CD}^{+}{ }^{+} \mathrm{T}$-cells 'naturally', the physiopathology of other neurodegenerative diseases, such as ALS, is associated with the participation of anti-inflammatory $\mathrm{CD} 4^{+}$T-cells that delay the neurodegenerative process. Thus, current evidence supports the hypothesis that the involvement of a $\mathrm{CD}^{+}{ }^{+}$T-cell-mediated response against CNS antigens constitutes a key component for the progression of the neurodegenerative process. Furthermore, an increasing number of studies have shown the relevance of peripheral monocytes/macrophages in the progression of neuroinflammation and their therapeutic potential for neurodegenerative disorders. According to this notion, immunoregulatory strategies to attenuate inflammatory $\mathrm{CD}^{+}$T-cells or M1 monocytes/macrophages and to strengthen the function of M2 monocytes/macrophages or Tregs specific for CNS antigens involved in neurodegenerative disorders should be considered in future therapies.

\section{Abbreviations}

$A \beta$ : $\beta$-amyloid peptide; AD: Alzheimer's disease; ALS: amyotrophic lateral sclerosis; APCs: antigen-presenting cells; BBB: blood-brainbarrier; BDNF: brain-derived neurotrophic factor; CA1: cornu ammonis area 1; CCLn: C-C chemokine ligand $n$; CCRn: C-C chemokine receptor $n$; CDn: cluster of differentiation n; CD4KO: CD4 knockout; CNS: central nervous system; DnR: dopamine receptor n; DnRKO: DnR knockout; EAE: experimental autoimmune encephalomyelitis; GDNF: glial cell-derived neurotrophic factor; GM-CSF: granulocyte macrophage-colony stimulating factor; IFN- : interferon- $\gamma$; IGF-1: insulin-like growth factor 1 ; IL-n: interleukin- $n$; LPS: lipopolysaccharide; MHC: major histocompatibility complex; MPTP: 1-methyl-4-phenyl-1,2,3,6-tetrahydropyridine; MS: multiple sclerosis; mSOD1: mutant SOD1; NADPH: nicotinamide adenine dinucleotide phosphate; NF-KB: nuclear factor kappa-light-chain-enhancer of activated B-cells; PD: Parkinson's disease; RAGn: recombination-activating-gen-n; RAGnKO: RAGn knockout; RNS: reactive nitrogen species; ROS: reactive oxygen species; SNpc: substantia nigra pars compacta; SOD1: superoxide dismutase 1; TCR: T-cell receptor; TCRßKO: TCR $\beta$-chain knockout; Thn: T-helper $n$; TLR: toll-like receptor; TNF-a: tumor necrosis factor-a; WT: wild type. 


\section{Competing interests}

The authors declare that they have no competing interests.

\section{Authors' contributions}

$\mathrm{HG}$ and RP have contributed equally to the conception of the main body of the manuscript, design of the structure, acquisition of data, analysis and interpretation of data. In addition, HG made the illustration (Figure 1) of this manuscript. RP wrote the sections of introduction and conclusion as well as the abstract of this manuscript. Both authors read and approved the final manuscript.

\section{Authors' information}

$\mathrm{HG}$ is PhD performing a postdoctoral training supervised by RP in the Laboratory of Neuroimmunology of the Fundación Ciencia \& Vida. RP is the Principal Investigator of the Laboratory of Neuroimmunology, Associate Investigator at Fundación Ciencia \& Vida and Professor at Universidad Andrés Bello.

\section{Acknowledgements}

This work was supported by grants 1130271 from FONDECYT and PFB-16 from CONICYT. Both grants contribute to HG and RP salaries and both grants funded publication costs.

\section{Received: 17 September 2014 Accepted: 12 November 2014}

\section{(1)}

\section{References}

1. Lucin KM, Wyss-Coray T: Immune activation in brain aging and neurodegeneration: too much or too little? Neuron 2009, 64:110-122.

2. Gonzalez H, Elgueta D, Montoya A, Pacheco R: Neuroimmune regulation of microglial activity involved in neuroinflammation and neurodegenerative diseases. J Neuroimmunol 2014, 274:1-13.

3. Qian L, Tan KS, Wei SJ, Wu HM, Xu Z, Wilson B, Lu RB, Hong JS, Flood PM: Microglia-mediated neurotoxicity is inhibited by morphine through an opioid receptor-independent reduction of NADPH oxidase activity. J Immunol 2007, 179:1198-1209.

4. Ferrari CC, Pott Godoy MC, Tarelli R, Chertoff M, Depino AM, Pitossi FJ: Progressive neurodegeneration and motor disabilities induced by chronic expression of IL-1beta in the substantia nigra. Neurobiol Dis 2006, 24:183-193.

5. Gordon R, Anantharam V, Kanthasamy AG, Kanthasamy A: Proteolytic activation of proapoptotic kinase protein kinase Cdelta by tumor necrosis factor alpha death receptor signaling in dopaminergic neurons during neuroinflammation. J Neuroinflammation 2012, 9:82.

6. Magro F, Fraga S, Ribeiro T, Soares-da-Silva P: Decreased availability of intestinal dopamine in transmural colitis may relate to inhibitory effects of interferon-gamma upon L-DOPA uptake. Acta Physio/ Scand 2004, 180:379-386.

7. Ostanin DV, Bao J, Koboziev I, Gray L, Robinson-Jackson SA, KosloskiDavidson M, Price VH, Grisham MB: T cell transfer model of chronic colitis: concepts, considerations, and tricks of the trade. Am J Physiol Gastrointest Liver Physiol 2009, 296:G135-G146.

8. Tahara K, Kim HD, Jin JJ, Maxwell JA, Li L, Fukuchi K: Role of toll-like receptor signalling in Abeta uptake and clearance. Brain 2006, 129:3006-3019.

9. Panaro MA, Lofrumento DD, Saponaro C, De Nuccio F, Cianciulli A, Mitolo V, Nicolardi G: Expression of TLR4 and CD14 in the central nervous system (CNS) in a MPTP mouse model of Parkinson's-like disease. Immunopharmacol Immunotoxicol 2008, 30:729-740.

10. Querfurth HW, LaFerla FM: Alzheimer's disease. N Engl J Med 2010, 362:329-344.

11. Braak H, Del Tredici K, Rub U, de Vos RA, Jansen Steur EN, Braak E: Staging of brain pathology related to sporadic Parkinson's disease. Neurobiol Aging 2003, 24:197-211.

12. Saccon RA, Bunton-Stasyshyn RK, Fisher EM, Fratta P: Is SOD1 loss of function involved in amyotrophic lateral sclerosis? Brain 2013, 136:2342-2358.

13. Lu L, Lan Q, Li Z, Zhou X, Gu J, Li Q, Wang J, Chen M, Liu Y, Shen Y, Brand DD, Ryffel B, Horwitz DA, Quismorio FP, Liu Z, Li B, Olsen NJ, Zheng SG: Critical role of all-trans retinoic acid in stabilizing human natural regulatory T cells under inflammatory conditions. Proc Natl Acad Sci U S A 2014, 111:E3432-E3440.
14. Appel SH: CD4+ T cells mediate cytotoxicity in neurodegenerative diseases. J Clin Invest 2009, 119:13-15.

15. Reynolds AD, Stone DK, Mosley RL, Gendelman HE: Proteomic studies of nitrated alpha-synuclein microglia regulation by CD4 + CD25+ T cells. J Proteome Res 2009, 8:3497-3511.

16. Browne TC, McQuillan K, McManus RM, O'Reilly JA, Mills KH, Lynch MA: IFN-gamma production by amyloid beta-specific Th1 cells promotes microglial activation and increases plaque burden in a mouse model of Alzheimer's disease. J Immunol 2013, 190:2241-2251.

17. Gonzalez H, Contreras F, Prado C, Elqueta D, Franz D, Bernales S, Pacheco R: Dopamine receptor D3 expressed on CD4+ T cells favors neurodegeneration of dopaminergic neurons during Parkinson's disease. J Immunol 2013, 190:5048-5056.

18. Dardalhon V, Korn T, Kuchroo VK, Anderson AC: Role of Th1 and Th17 cells in organ-specific autoimmunity. J Autoimmun 2008, 31:252-256.

19. Paul WE: What determines Th2 differentiation, in vitro and in vivo? Immunol Cell Biol 2010, 88:236-239.

20. Beers DR, Henkel JS, Zhao W, Wang J, Appel SH: CD4+ T cells support glial neuroprotection, slow disease progression, and modify glial morphology in an animal model of inherited ALS. Proc Natl Acad Sci U S A 2008, 105:15558-15563.

21. Derecki NC, Cardani AN, Yang CH, Quinnies KM, Crihfield A, Lynch KR, Kipnis $\mathrm{J}$ : Regulation of learning and memory by meningeal immunity: a key role for IL-4. J Exp Med 2010, 207:1067-1080.

22. Baruch K, Ron-Harel N, Gal H, Deczkowska A, Shifrut E, Ndifon W, Mirlas-Neisberg N, Cardon M, Vaknin I, Cahalon L, Berkutzki T, Mattson MP, Gomez-Pinilla F, Friedman N, Schwartz M: CNS-specific immunity at the choroid plexus shifts toward destructive Th2 inflammation in brain aging. Proc Natl Acad Sci U S A 2013, 110:2264-2269.

23. Chiu IM, Chen A, Zheng Y, Kosaras B, Tsiftsoglou SA, Vartanian TK, Brown RH $\mathrm{Jr}$, Carroll MC: $\mathrm{T}$ lymphocytes potentiate endogenous neuroprotective inflammation in a mouse model of ALS. Proc Natl Acad Sci U S A 2008, 105:17913-17918.

24. Nikolic W, Bai Y, Obregon D, Hou H, Mori T, Zeng J, Ehrhart J, Shytle RD, Giunta B, Morgan D, Town T, Tan J: Transcutaneous beta-amyloid immunization reduces cerebral beta-amyloid deposits without $\mathrm{T}$ cell infiltration and microhemorrhage. Proc Natl Acad Sci U S A 2007, 104:2507-2512.

25. Yang H, Xie Z, Wei L, Bi J: Systemic transplantation of human umbilical cord derived mesenchymal stem cells-educated T regulatory cells improved the impaired cognition in AbetaPPswe/PS1dE9 transgenic mice. PLoS One 2013, 8:e69129.

26. Reynolds AD, Stone DK, Hutter JA, Benner EJ, Mosley RL, Gendelman HE: Regulatory $T$ cells attenuate Th17 cell-mediated nigrostriatal dopaminergic neurodegeneration in a model of Parkinson's disease. J Immunol 2010, 184:2261-2271.

27. Petermann F, Rothhammer V, Claussen MC, Haas JD, Blanco LR, Heink S, Prinz I, Hemmer B, Kuchroo VK, Oukka M, Korn T: gammadelta T cells enhance autoimmunity by restraining regulatory $T$ cell responses via an interleukin-23-dependent mechanism. Immunity 2010, 33:351-363.

28. Fransson M, Piras E, Burman J, Nilsson B, Essand M, Lu B, Harris RA, Magnusson PU, Brittebo E, Loskog AS: CAR/FoxP3-engineered T regulatory cells target the CNS and suppress EAE upon intranasal delivery. J Neuroinflammation 2012, 9:112.

29. Polman CH, Reingold SC, Edan G, Filippi M, Hartung HP, Kappos L, Lublin FD, Metz LM, McFarland HF, O'Connor PW, Sandberg-Wollheim M, Thompson AJ, Weinshenker BG, Wolinsky JS: Diagnostic criteria for multiple sclerosis: 2005 revisions to the 'McDonald Criteria'. Ann Neurol 2005, 58:840-846.

30. Goverman J: Autoimmune T cell responses in the central nervous system. Nat Rev Immunol 2009, 9:393-407.

31. Chastain EM, Duncan DS, Rodgers JM, Miller SD: The role of antigen presenting cells in multiple sclerosis. Biochim Biophys Acta 2011, 1812:265-274

32. Jadidi-Niaragh F, Mirshafiey A: Histamine and histamine receptors in pathogenesis and treatment of multiple sclerosis. Neuropharmacology 2010, 59:180-189.

33. Prado C, Contreras F, Gonzalez H, Diaz P, Elgueta D, Barrientos M, Herrada AA, Lladser A, Bernales S, Pacheco R: Stimulation of dopamine receptor D5 expressed on dendritic cells potentiates Th17-mediated immunity. $\mathrm{J}$ Immunol 2012, 188:3062-3070. 
34. Reboldi A, Coisne C, Baumjohann D, Benvenuto F, Bottinelli D, Lira S, Uccelli A, Lanzavecchia A, Engelhardt B, Sallusto F: C-C chemokine receptor 6-regulated entry of $\mathrm{TH}-17$ cells into the $\mathrm{CNS}$ through the choroid plexus is required for the initiation of EAE. Nat Immuno/ 2009, 10:514-523

35. Murphy AC, Lalor SJ, Lynch MA, Mills KH: Infiltration of Th1 and Th17 cells and activation of microglia in the CNS during the course of experimental autoimmune encephalomyelitis. Brain Behav Immun 2010, 24:641-651

36. Carson MJ, Doose JM, Melchior B, Schmid CD, Ploix CC: CNS immune privilege: hiding in plain sight. Immunol Rev 2006, 213:48-65.

37. Iruretagoyena MI, Sepulveda SE, Lezana JP, Hermoso M, Bronfman M, Gutierrez MA, Jacobelli SH, Kalergis AM: Inhibition of nuclear factorkappa B enhances the capacity of immature dendritic cells to induce antigen-specific tolerance in experimental autoimmune encephalomyelitis. J Pharmacol Exp Ther 2006, 318:59-67.

38. Codarri L, Gyulveszi G, Tosevski V, Hesske L, Fontana A, Magnenat L, Suter T, Becher B: RORgammat drives production of the cytokine GM-CSF in helper T cells, which is essential for the effector phase of autoimmune neuroinflammation. Nat Immunol 2011, 12:560-567.

39. Cravens PD, Hussain RZ, Zacharias TE, Ben LH, Herndon E, Vinnakota R, Lambracht-Washington D, Nessler S, Zamvil SS, Eagar TN, Stuve O: Lymph node-derived donor encephalitogenic CD4+ T cells in C57BL/6 mice adoptive transfer experimental autoimmune encephalomyelitis highly express GM-CSF and T-bet. J Neuroinflammation 2011, 8:73

40. Lee Y, Awasthi A, Yosef N, Quintana FJ, Xiao S, Peters A, Wu C, Kleinewietfeld M, Kunder S, Hafler DA, Sobel RA, Regev A, Kuchroo VK: Induction and molecular signature of pathogenic TH17 cells. Nat Immunol 2012, 13:991-999.

41. Weiss HA, Millward JM, Owens T: CD8+ T cells in inflammatory demyelinating disease. J Neuroimmunol 2007, 191:79-85.

42. Fletcher JM, Lalor SJ, Sweeney CM, Tubridy N, Mills KH: T cells in multiple sclerosis and experimental autoimmune encephalomyelitis. Clin Exp Immunol 2010, 162:1-11.

43. Varthaman A, Clement M, Khallou-Laschet J, Fornasa G, Gaston AT, Dussiot M, Caligiuri G, Cantor H, Kaveri S, Nicoletti A: Physiological induction of regulatory Qa-1-restricted CD8+ T cells triggered by endogenous CD4+ T cell responses. PLoS One 2011, 6:e21628.

44. Chen ML, Yan BS, Kozoriz D, Weiner HL: Novel CD8+ Treg suppress EAE by TGF-beta- and IFN-gamma-dependent mechanisms. Eur J Immunol 2009, 39:3423-3435.

45. Najafian N, Chitnis T, Salama AD, Zhu B, Benou C, Yuan X, Clarkson MR, Sayegh MH, Khoury SJ: Regulatory functions of CD8 + CD28- T cells in an autoimmune disease model. J Clin Invest 2003, 112:1037-1048.

46. Lee $Y H$, Ishida $Y$, Rifa'i M, Shi Z, Isobe K, Suzuki H: Essential role of CD8 + $\mathrm{CD} 122+$ regulatory $T$ cells in the recovery from experimental autoimmune encephalomyelitis. J Immunol 2008, 180:825-832.

47. Bas J, Calopa M, Mestre M, Mollevi DG, Cutillas B, Ambrosio S, Buendia E: Lymphocyte populations in Parkinson's disease and in rat models of parkinsonism. J Neuroimmunol 2001, 113:146-152.

48. Fiszer U, Mix E, Fredrikson $\mathrm{S}$, Kostulas $\mathrm{V}$, Olsson $\mathrm{T}$, Link $\mathrm{H}$ : gamma delta $+\mathrm{T}$ cells are increased in patients with Parkinson's disease. J Neurol Sci 1994, 121:39-45.

49. McGeer PL, Itagaki S, Akiyama H, McGeer EG: Rate of cell death in parkinsonism indicates active neuropathological process. Ann Neurol 1988, 24:574-576.

50. Brochard V, Combadiere B, Prigent A, Laouar $Y$, Perrin A, Beray-Berthat V, Bonduelle O, Alvarez-Fischer D, Callebert J, Launay JM, Duyckaerts C, Flavell RA, Hirsch EC, Hunot S: Infiltration of CD4+ lymphocytes into the brain contributes to neurodegeneration in a mouse model of Parkinson disease. J Clin Invest 2009, 119:182-192.

51. Kurkowska-Jastrzebska I, Wronska A, Kohutnicka M, Czlonkowski A, Czlonkowska A: The inflammatory reaction following 1-methyl-4-phenyl1,2,3, 6-tetrahydropyridine intoxication in mouse. Exp Neurol 1999 156:50-61.

52. Sanchez-Guajardo V, Febbraro F, Kirik D, Romero-Ramos M: Microglia acquire distinct activation profiles depending on the degree of alphasynuclein neuropathology in a rAAV based model of Parkinson's disease. PLoS One 2010, 5:e8784.

53. Benner EJ, Banerjee R, Reynolds AD, Sherman S, Pisarev VM, Tsiperson V Nemachek C, Ciborowski P, Przedborski S, Mosley RL, Gendelman HE:
Nitrated alpha-synuclein immunity accelerates degeneration of nigral dopaminergic neurons. PLoS One 2008, 3:e1376

54. Pacheco R, Gallart T, Lluis C, Franco R: Role of glutamate on T-cell mediated immunity. J Neuroimmunol 2007, 185:9-19.

55. Harms AS, Cao S, Rowse AL, Thome AD, Li X, Mangieri LR, Cron RQ, Shacka J, Raman C, Standaert DG: MHCII is required for alpha-synuclein-induced activation of microglia, CD4 T cell proliferation, and dopaminergic neurodegeneration. J Neurosci 2013, 33:9592-9600.

56. Chen Y, Ni YY, Liu J, Lu JW, Wang F, Wu XL, Gu MM, Lu ZY, Wang ZG, Ren $\mathrm{ZH}$ : Dopamine receptor 3 might be an essential molecule in 1-methyl-4phenyl-1,2,3,6-tetrahydropyridine-induced neurotoxicity. BMC Neurosci 2013, 14:76.

57. Barcia C, Ros CM, Annese V, Gomez A, Ros-Bernal F, Aguado-Yera D, Martinez-Pagan ME, de Pablos $V$, Fernandez-Villalba E, Herrero MT: IFN-gamma signaling, with the synergistic contribution of TNF-alpha, mediates cell specific microglial and astroglial activation in experimental models of Parkinson's disease. Cell Death Dis 2011, 2:e142.

58. Reynolds AD, Banerjee R, Liu J, Gendelman HE, Mosley RL: Neuroprotective activities of CD4 + CD25+ regulatory T cells in an animal model of Parkinson's disease. J Leukoc Biol 2007, 82:1083-1094.

59. Reynolds AD, Stone DK, Mosley RL, Gendelman HE: Nitrated \{alpha\} synuclein-induced alterations in microglial immunity are regulated by CD4+ T cell subsets. J Immunol 2009, 182:4137-4149.

60. Arnon R, Aharoni R: Mechanism of action of glatiramer acetate in multiple sclerosis and its potential for the development of new applications. Proc Natl Acad Sci U S A 2004, 101(Suppl 2):14593-14598.

61. Laurie C, Reynolds A, Coskun O, Bowman E, Gendelman HE, Mosley RL: CD4+ T cells from Copolymer-1 immunized mice protect dopaminergic neurons in the 1-methyl-4-phenyl-1,2,3,6-tetrahydropyridine model of Parkinson's disease. J Neuroimmunol 2007, 183:60-68.

62. Monsonego A, Imitola J, Petrovic S, Zota V, Nemirovsky A, Baron R, Fisher Y, Owens T, Weiner HL: Abeta-induced meningoencephalitis is IFN-gammadependent and is associated with T cell-dependent clearance of Abeta in a mouse model of Alzheimer's disease. Proc Natl Acad Sci U S A 2006, 103:5048-5053.

63. Togo T, Akiyama H, Iseki E, Kondo H, Ikeda K, Kato M, Oda T, Tsuchiya K, Kosaka K: Occurrence of T cells in the brain of Alzheimer's disease and other neurological diseases. J Neuroimmunol 2002, 124:83-92.

64. Monsonego A, Zota V, Karni A, Krieger Jl, Bar-Or A, Bitan G, Budson AE, Sperling $\mathrm{R}$, Selkoe DJ, Weiner HL: Increased T cell reactivity to amyloid beta protein in older humans and patients with Alzheimer disease. J Clin Invest 2003, 112:415-422.

65. Schenk D, Barbour R, Dunn W, Gordon G, Grajeda H, Guido T, Hu K, Huang J, Johnson-Wood K, Khan K, Kholodenko D, Lee M, Liao Z, Lieberburg I, Motter R, Mutter L, Soriano F, Shopp G, Vasquez N, Vandevert C, Walker S, Wogulis M, Yednock T, Games D, Seubert P: Immunization with amyloidbeta attenuates Alzheimer-disease-like pathology in the PDAPP mouse. Nature 1999, 400:173-177.

66. Baruch $K$, Schwartz M: CNS-specific T cells shape brain function via the choroid plexus. Brain Behav Immun 2013, 34:11-16.

67. Shechter R, Miller O, Yovel G, Rosenzweig N, London A, Ruckh J, Kim KW, Klein E, Kalchenko V, Bendel P, Lira SA, Jung S, Schwartz M: Recruitment of beneficial M2 macrophages to injured spinal cord is orchestrated by remote brain choroid plexus. Immunity 2013, 38:555-569.

68. Saresella M, Calabrese E, Marventano I, Piancone F, Gatti A, Calvo MG, Nemni R, Clerici M: PD1 negative and PD1 positive CD4+ T regulatory cells in mild cognitive impairment and Alzheimer's disease. J Alzheimers Dis 2010, 21:927-938.

69. Goldeck D, Larbi A, Pellicano M, Alam I, Zerr I, Schmidt C, Fulop T, Pawelec $\mathrm{G}$ : Enhanced chemokine receptor expression on leukocytes of patients with Alzheimer's disease. PLOS One 2013, 8:e66664.

70. Zhang J, Ke KF, Liu Z, Qiu YH, Peng YP: Th17 cell-mediated neuroinflammation is involved in neurodegeneration of abeta1-42-induced Alzheimer's disease model rats. PLOS One 2013, 8:e75786.

71. Gurney ME, Pu H, Chiu AY, Dal Canto MC, Polchow CY, Alexander DD, Caliendo J, Hentati A, Kwon YW, Deng HX, Chen W, Zhai P, Sufit RL, Siddique T: Motor neuron degeneration in mice that express a human Cu, Zn superoxide dismutase mutation. Science 1994, 264:1772-1775.

72. Mantovani S, Garbelli S, Pasini A, Alimonti D, Perotti C, Melazzini M, Bendotti C, Mora G: Immune system alterations in sporadic amyotrophic lateral 
sclerosis patients suggest an ongoing neuroinflammatory process. J Neuroimmunol 2009, 210:73-79.

73. Wan YY, Flavell RA: Regulatory T-cell functions are subverted and converted owing to attenuated Foxp3 expression. Nature 2007, 445:766-770.

74. Henkel JS, Beers DR, Wen S, Rivera AL, Toennis KM, Appel JE, Zhao W, Moore DH, Powell SZ, Appel SH: Regulatory T-lymphocytes mediate amyotrophic lateral sclerosis progression and survival. EMBO Mol Med 2013, 5:64-79.

75. Beers DR, Henkel JS, Zhao W, Wang J, Huang A, Wen S, Liao B, Appel SH: Endogenous regulatory $T$ lymphocytes ameliorate amyotrophic lateral sclerosis in mice and correlate with disease progression in patients with amyotrophic lateral sclerosis. Brain 2011, 134:1293-1314.

76. Huber S, Schramm C, Lehr HA, Mann A, Schmitt S, Becker C, Protschka M, Galle PR, Neurath MF, Blessing M: Cutting edge: TGF-beta signaling is required for the in vivo expansion and immunosuppressive capacity of regulatory CD4 + CD25+ T cells. J Immunol 2004, 173:6526-6531.

77. Chan LL, Cheung BK, Li JC, Lau AS: A role for STAT3 and cathepsin S in IL-10 down-regulation of IFN-gamma-induced MHC class II molecule on primary human blood macrophages. J Leukoc Biol 2010, 88:303-311.

78. Martinez FO, Gordon S: The M1 and M2 paradigm of macrophage activation: time for reassessment. F1000prime Reports 2014, 6:13.

79. Noh H, Jeon J, Seo H: Systemic injection of LPS induces region-specific neuroinflammation and mitochondrial dysfunction in normal mouse brain. Neurochem Int 2014, 69:35-40.

80. Zhou L, Miranda-Saksena M, Saksena NK: Viruses and neurodegeneration. Virol J 2013, 10:172.

81. Mazzini E, Massimiliano L, Penna G, Rescigno M: Oral tolerance can be established via gap junction transfer of fed antigens from CX3CR1(+) macrophages to CD103(+) dendritic cells. Immunity 2014, 40:248-261.

82. Nishimura M, Kuno S, Mizuta I, Ohta M, Maruyama H, Kaji R, Kawakami H: Influence of monocyte chemoattractant protein 1 gene polymorphism on age at onset of sporadic Parkinson's disease. Mov Disord 2003, 18:953-955.

83. Hirota K, Turner JE, Villa M, Duarte JH, Demengeot J, Steinmetz OM, Stockinger B: Plasticity of Th17 cells in Peyer's patches is responsible for the induction of T cell-dependent IgA responses. Nat Immunol 2013 14:372-379

84. Zhao Y, Haney MJ, Gupta R, Bohnsack JP, He Z, Kabanov AV, Batrakova EV: GDNF-transfected macrophages produce potent neuroprotective effects in Parkinson's disease mouse model. PLoS One 2014, 9:e106867.

85. Gomes AC, Bueno AA, de Souza RG, Mota JF: Gut microbiota, probiotics and diabetes. Nutr J 2014, 13:60

86. Rakoff-Nahoum S, Paglino J, Eslami-Varzaneh F, Edberg S, Medzhitov R: Recognition of commensal microflora by toll-like receptors is required for intestinal homeostasis. Cell 2004, 118:229-241.

87. Longman RS, Yang Y, Diehl GE, Kim SV, Littman DR: Microbiota: host interactions in mucosal homeostasis and systemic autoimmunity. Cold Spring Harb Symp Quant Biol 2013, 78:193-201.

88. Berer K, Mues M, Koutrolos M, Rasbi ZA, Boziki M, Johner C, Wekerle H, Krishnamoorthy G: Commensal microbiota and myelin autoantigen cooperate to trigger autoimmune demyelination. Nature 2011, 479:538-541.

89. Taneja V: Arthritis susceptibility and the gut microbiome. FEBS Lett, in press.

90. Ahn M, Yang W, Kim H, Jin JK, Moon C, Shin T: Immunohistochemical study of arginase- 1 in the spinal cords of Lewis rats with experimental autoimmune encephalomyelitis. Brain Res 2012, 1453:77-86.

91. Denning TL, Norris BA, Medina-Contreras O, Manicassamy S, Geem D, Madan R, Karp CL, Pulendran B: Functional specializations of intestinal dendritic cell and macrophage subsets that control Th17 and regulatory $\mathrm{T}$ cell responses are dependent on the T cell/APC ratio, source of mouse strain, and regional localization. J Immunol 2011, 187:733-747.

92. Miron VE, Boyd A, Zhao JW, Yuen TJ, Ruckh JM, Shadrach JL, van Wijngaarden P, Wagers AJ, Williams A, Franklin RJ, ffrench-Constant C: M2 microglia and macrophages drive oligodendrocyte differentiation during CNS remyelination. Nat Neurosci 2013, 16:1211-1218.

doi:10.1186/s12974-014-0201-8

Cite this article as: González and Pacheco: T-cell-mediated regulation of neuroinflammation involved in neurodegenerative diseases. Journal of Neuroinflammation 2014 11:201.

\section{Submit your next manuscript to BioMed Central and take full advantage of:}

- Convenient online submission

- Thorough peer review

- No space constraints or color figure charges

- Immediate publication on acceptance

- Inclusion in PubMed, CAS, Scopus and Google Scholar

- Research which is freely available for redistribution 